\title{
A Comparison of Modeled and Measured Energ Use in Hybrid Electric Vehicles
}

Matthew Cuddy

National Renewable Energy Laboratory

Prepared for the 1995 SAE International Congress and Exposition, Detroit, Michigan

February 27 - March 3, 1995

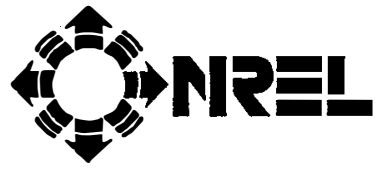

National Renewable Energy Laboratory 1617 Cole Boulevard Golden, Colorado 80401-3393

A national laboratory of the U.S. Department of Energy Managed by the Midwest Research Institute for the U.S. Department of Energy under Contract No. DE-AC36-83CH10093 


\section{NOTICE}

This report was prepared as an account of work sponsored by an agency of the United States government. Neither the United States government nor any agency thereof, nor any of their employees, makes any warranty, express or implied, or assumes any legal liability or responsibility for the accuracy, completeness, or usefulness of any information, apparatus, product, or process disclosed, or represents that its use would not infringe privately owned rights. Reference herein to any specific commercial product, process, or service by trade name, trademark, manufacturer, or otherwise does not necessarily constitute or imply its endorsement, recommendation, or favoring by the United States government or any agency thereof. The views and opinions of authors expressed herein do not necessarily state or reflect those of the United States government or any agency thereof.

Available to DOE and DOE contractors from:

Office of Scientific and Technical Information (OSTI)

P.O. Box 62

Oak Ridge, TN 37831

Prices available by calling (615) $576-8401$

Available to the public from:

National Technical Information Service (NTIS)

U.S. Department of Commerce

5285 Port Royal Road

Springfield, VA 22161

(703) $487-4650$ 


\title{
A Comparison of Modeled and Measured Energy Use in Hybrid Electric Vehicles
}

\author{
Matthew Cuddy \\ National Renewable Energy Laboratory
}

\begin{abstract}
CarSim 2.5.4, written by AeroVironment, Inc. of Monrovia, California and SIMPLEV 3.0, written by Idaho National Engineering Laboratory were used to simulate two series-configured hybrid electric vehicles that competed in the 1994 Hybrid Electric Vehicle Challenge. Vehicle speed and battery energy use were measured over a $0.2-\mathrm{km}$ maximum effort acceleration and a 58-km range event. The simulations' predictions are compared to each other and to measured data. A rough uncertainty analysis of the validation is presented. The programs agree with each other to within $5 \%$ and with the measured energy data within the uncertainty of the experiment.
\end{abstract}

\section{INTRODUCTION}

The objective of this paper is to evaluate the accuracy of two hybrid electric vehicle (HEV) performance simulation programs, and to alert the reader to considerations critical to such validation efforts.

Interest and investment in HEV development continue to increase. Hybrids are seen by some as a viable, highefficiency compromise between full-performance, conventional internal combustion engine-driven vehicles and lower-performance electric vehicles (powered by currently commercially available batteries). HEVs are an important part of the development efforts that are part of the Partnership for the New Generation of Vehicles announced by President Clinton.

As HEV development efforts grow, so does work in the computer simulation of HEVs. Computer simulation has been applied to aircraft design, structural analysis, fluid flow analysis, and conventional automobile design. It is widely recognized as a time- and cost-saving tool that helps reduce the number of actual experiments that must be performed on a system.

An engineer may waste time and money, however, if he uses unvalidated simulations to make time or money investment decisions. To paraphrase a friend in the chemical processing industry, all simulations are wrong, but some are useful. Computer simulations must make some simplifying assumptions that allow a mathematical description of the system being simulated. How useful the simulation is depends upon how much the assumptions affect the results. The aim of a validation effort is to determine how closely the simulation in question approximates reality.

This paper is devoted to validation of two HEV simulations and to considerations important to any HEV simulation validation. The following sections will describe the experimental data collection that took place, discuss uncertainty and a rough uncertainty analysis, compare the simulations' calculated results to measured data, and present conclusions and recommendations.

\section{EXPERIMENTAL PROCEDURE}

The general procedure followed in this validation effort measured the speed profiles and battery energy use of two HEVs competing at the 1994 Hybrid Electric Vehicle Challenge, collected data describing the components of the two HEVs, and modeled the vehicles by prescribing the speed data collected. The two HEVs are those assembled by the student teams at Pennsylvania State University (Penn State) and California State Polytechnic University-Pomona (Cal PolyPomona). Penn State's vehicle's zero-emission vehicle (ZEV) performance in the $58-\mathrm{km}$ range event only is computed, as is Cal Poly-Pomona's performance in two 0.2-km accelerations, one as an HEV and one as a ZEV.

Two data acquisition systems (DASs) were used at the Challenge. A DAS built by Instrumental Solutions measured speed, battery current and voltage, generator current and voltage in 1-second increments. A DAS built by Cruising Equipment measured total battery energy and ampere hours.

Speed measurements were taken using magnets mounted to the drive axle half-shaft and a pickup. Speeds in the maximum effort acceleration were averaged using 3 points at time, centered in time. Speeds measured in the 58-km-long range event were averaged using 5 points, centered in time. This averaged speed profile was again averaged using 3 points centered in time. This processing was necessary to reduce noise in the data before using them as inputs for the simulations.

The simulation programs used in this study are SIMPLEV 3.0, written by Idaho National Engineering Laboratory, and 
CarSim 2.5.4, written by AeroVironment Inc. SIMPLEV runs on an IBM-compatible PC while CarSim runs on an Apple Macintosh. The programs use empirical efficiency maps and other data to model series-configured HEVs.

The programs assume a vehicle layout as shown in Figure 1. The bus either accepts energy from or delivers it to the batteries and electric motor via the motor controller. The bus accepts energy only from the generator, and only when the internal combustion engine is on. The bidirectional arrows that connect the controller, motor, and transmission indicate that regenerative braking is assumed possible.

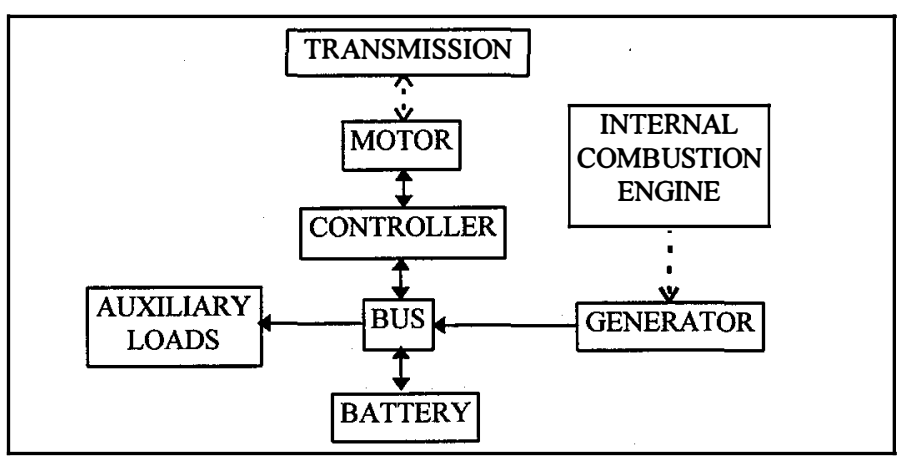

Figure 1. HEV schematic. Dotted lines indicate mechanical energy transfer, solid lines indicate electrical energy transfer (adapted from reference 1.)

The approach SIMPLEV and CarSim use is similar to that used in many other simulation programs at universities and national laboratories.[2][3][4] The programs accept input data to describe the vehicle's trip, the vehicle itself, the transmission, electric motor, motor controller, battery pack, generator, and internal combustion engine. The input data may be in the form of a scalar efficiency, for example, or a component efficiency map, with efficiency as a function of torque and rotational speed. SIMPLEV and CarSim both accept detailed component efficiency maps.

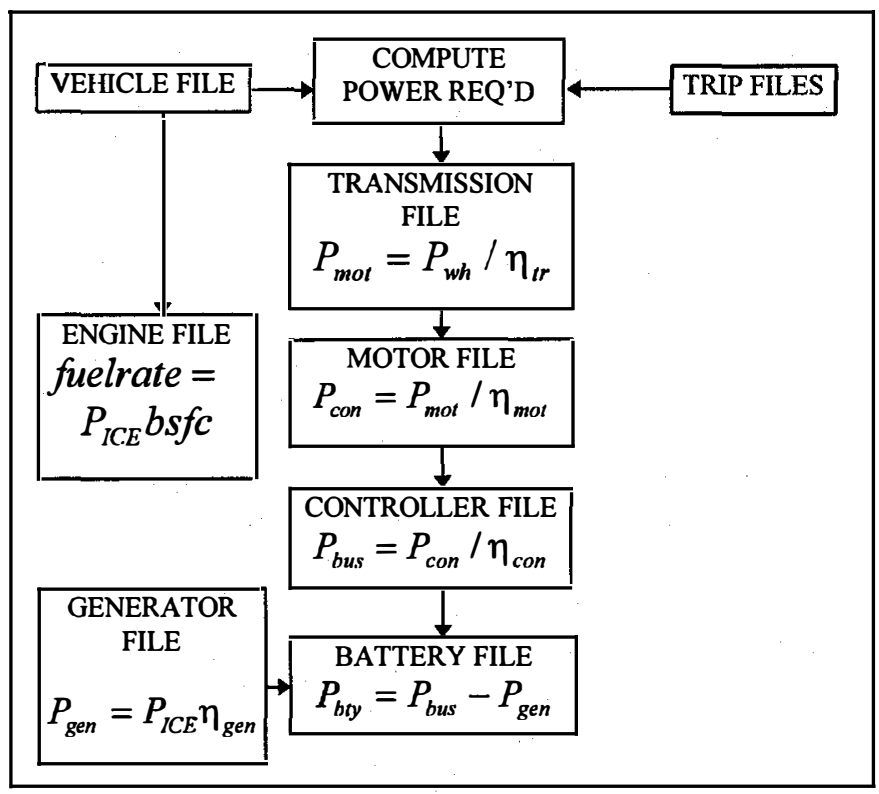

Figure 2. Block diagram of information flow in SIMPLEV

Figure 2 depicts SIMPLEV's data processing procedure. The trip files include pairs of time and speed points (at a userspecified time step) and pairs of hill grade and distance points.
The vehicle file contains information such as coefficient of drag, frontal area, and curb weight. SIMPLEV uses twodimensional look-up tables that contain component efficiency for pairs of electric motor RPM and torque for the transmission, electric motor, and electric motor controller. The battery pack is described by a table of intemal resistance and open circuit voltage as a function of the battery pack's depth of discharge. See reference 1 for a more detailed description of SIMPLEV's algorithms.

\section{ROLE OF UNCERTAINTY IN VALIDATION}

The goal of validation is to determine how closely the simulation approximates reality. To know this, we must know the true value against which the simulation's output will be compared. More realistically, we must know in what range this value likely falls. And of course, a computer program is only as good as its input; therefore we must know how accurate the inputs are. The uncertainty considerations here are not believed to be an exhaustive list. They do include main sources of potential error and are meant to alert the reader to the significance of uncertainty analysis in validation.

Input data such as component efficiencies and operating limits are measured quantities, and as such have some measurement uncertainty associated with them. Consider an electric motor, for example. The particular motor used in the vehicle may not have been tested, rather it may be one of a manufacturer's lot of motors, some fraction of which have been tested. In this case, some variation between the tested motors and the motor in question should be expected. Even if the motor used in the vehicle were tested, both bias and random uncertainty will exist in the test. Furthermore, the motor will likely be operated in an environment (temperature) dissimilar to that in which it was tested, introducing more uncertainty.

Significant uncertainty may also be introduced in applying the input data to the simulation program. The simulation user must fully understand how the program uses supplied data. For example, electric motor torque limits as a function of RPM are accepted by both SIMPLEV and CarSim, and to use the torque limits, the program user must interpret the manufacturer's data. It may be unclear whether the maximum torque is that maintainable for 1 minute, indefinitely, or for 5 seconds. The user may also introduce error by inputting or processing the data incorrectly.

Energy use data measured for comparison to the simulation predictions are also subject to measurement uncertainty. The data may be imprecise because of insufficient resolution, an inappropriate sampling rate, or random measuring equipment fluctuations. Inaccuracy may be caused by inappropriate calibration of the measurement equipment or by environmental effects. Interference is particularly significant in on-board vehicle data collection systems. Error may also be introduced by post-processing techniques.

\section{UNCERTAINTY ANALYSIS}

Where possible, bias uncertainty is separated from random uncertainty in the analysis described below. Bias and random uncertainties are propagated using Taylor series: 


$$
S_{r}^{2}=\left(\frac{\partial r}{\partial x} S_{x}\right)^{2}+\left(\frac{\partial r}{\partial y} S_{y}\right)^{2}
$$

where $S_{x}$ is the uncertainty in $x$, and $r=f(x, y)[5]$. Bias limits are simply added where appropriate, however. Special note is made of these instances. Bias limits, B, and random uncertainty limits, $R$, are combined into the total uncertainty $U$ by

$$
U^{2}=B^{2}+R^{2}
$$

INPUT DATA-Uncertainty in component specifications, in speed measurements, and those introduced by the user are considered.

Component Specifications-The sources of component data and estimated uncertainties are listed in Table 1. The effect of these uncertainties was estimated by modeling "best" and "worst" case vehicles. The best case vehicle was the most efficient possible given the uncertainty intervals in Table 1, and the worst case was the least efficient.

Table 1. Component Data: Sources of Information and Uncertainty Estimates

\begin{tabular}{|l|c|c|}
\hline \multicolumn{1}{|c|}{ Component } & Data Source & $\begin{array}{c}\text { Estimated } \\
\text { Uncertainty }\end{array}$ \\
\hline Cal Poly-Pomona: & student measurement & $\pm 35 \%$ \\
generator output & Advanced DC* & $\pm 5 \%$ \\
motor $\eta$ & estimate & $+2 /-4 \%$ \\
controller $\eta$ & estimate & $+2 /-4 \%$ \\
transmission $\eta$ & measured at Challenge & $\pm 1 \%$ \\
mass & estimate & $\pm 1 \%$ \\
inertial mass & estimate & $\pm 20 \%$ \\
coeff. of roll. resist. & student measurement \\
coeff. of aero. drag. & $\pm 10 \%$ \\
frontal area & student measurement & $\pm 10 \%$ \\
\hline Penn State: & Solectria* & $\pm 8 \%$ \\
motor $\eta$ & Solectria* & $\pm 8 \%$ \\
controller $\eta$ & estimate & $+2 /-4 \%$ \\
transmission $\eta$ & estimate & $\pm 1 \%$ \\
mass & estimate & $\pm 1 \%$ \\
inertial mass & Ford* & $\pm 20 \%$ \\
coeff. of roll. resist. & Ford* & neglected \\
coeff. of aero. drag & student estimate & $\pm 50 \%$ \\
frontal area & & \\
regenerative & measured at Challenge \\
braking fraction & sured \\
\hline indicates compont & \\
\hline
\end{tabular}

* indicates component manufacturer

The generator set output (for Cal Poly-Pomona) has a relatively high uncertainty associated with it. Both programs were used with a constant power output generator set model, but tests completed at Cal Poly-Pomona indicate that power varied with generator current and voltage. The means by which the internal combustion engine's output was regulated is unknown.

Measured Speed- Random error in vehicle speed includes the contribution by limited resolution above as well as observed scatter in a repeated distance measurement. The speed measurement equipment's resolution is one pulse, where one pulse (caused by the axle-mounted magnet passing the vehicle-chassis-mounted pickup) per second corresponds to 1.50 and $0.926 \mathrm{~km} / \mathrm{h}$ on the Cal Poly-Pomona and Penn State vehicles, respectively.

Bias error was introduced by uncertainty in the calibration.

The effect of this speed uncertainty on the programs' battery power calculations is calculated as follows:

$$
P_{b t y}=\frac{1}{\eta_{d}}\left(m_{i} \frac{\partial v}{\partial t}+m g C_{r r}+\frac{1}{2} \rho C_{D} A v^{2}\right) v
$$

where $\eta_{d}=\eta_{\text {motor }} \eta_{\text {controller }} \eta_{\text {transmission }}$ is the average efficiency at which electrical energy at the battery is converted to mechanical work at the tires, $m_{i}$ is the inertial mass of the vehicle, greater than the actual mass of the vehicle because it includes the inertia of spinning components, $m g$ is the weight of the vehicle, $C_{r r}$ is the tires' coefficient of rolling resistance, $\rho$ is air density, $C_{D}$ is the coefficient of aerodynamic drag, $A$ is the vehicle's frontal area, and $v$ is the vehicle speed. This equation assumes component efficiency independent of torque and speed.

The equation is dicretized, with the speed derivative approximated as $\left(v-v_{\text {prev }}\right) / \Delta t=v_{\text {diff }} / \Delta t . \quad V_{\text {diff }}$ is defined by this equation while $v_{\text {prev }}$ is the vehicle speed at the previous time step. $V$ and $v_{\text {diff }}$ are treated as independent variables with estimated random and bias uncertainties (the bias uncertainty in $v_{\text {diff }}$ is zero), and EQ (1) is applied.

This results in a random and bias uncertainty in the battery power that the codes compute. To compute the uncertainty in energy use for the entire trip, the random uncertainties in each time step are added in quadrature, as in EQ (1), and the bias limits are simply added.

User Error-The author has used SIMPLEV and CarSim for roughly nine months and has frequent communications with SIMPLEV's developer and other engineers who use CarSim. User error is assumed to be zero.

\section{MEASURED ENERGY USE DATA-Measurement} uncertainty is introduced by interference, random fluctuations in the measurement equipment, limited resolution, inappropriate sampling rates, and failures in calibration. The following discussion applies to the Instrumental Solutions DAS only. Uncertainty in the Cruising Equipment meter's measurements is estimated from readings taken on other vehicles at the 1994 Hybrid Electric Vehicle Challenge to be $10 \%$.

Random Error-Interference is a significant consideration for on-board vehicle DASs such as those used in this study. The effect of interference on the Instrumental Solutions system is estimated by considering the magnitude and frequency of readings far from expected values. Note that these outliers are not discarded. There are seven instances where the battery voltage jumps by a factor of two between 1-s readings without a corresponding change in current or the battery current reading is negative when there is no regenerative braking or other battery charging. These apparent errors occurred in $6 \%$ of the measurements considered. The random uncertainty in voltage and current readings was estimated at $20 \mathrm{~V}$ and $20 \mathrm{~A}$.

Random fluctuations in voltage and current readings were noted during constant voltage and constant current bench tests of the Instrumental Solutions DAS at the National Renewable Energy Laboratory (NREL). These fluctuations were roughly 
$1-3 \%$ over the course of $30 \mathrm{~s}$, and are considered to be lumped with the above uncertainty for this analysis.

The Instrumental Solutions DAS measures voltage with 2.0 $\mathrm{V}$ resolution and current with $3.9 \mathrm{~A}$ resolution. These resolutions contributed to the random error in power measurement .

Voltage and current are sampled at a rate of roughly 2500 $\mathrm{Hz}$. These readings were averaged every second by the DAS. During the hard accelerations for which the DAS was used, current can be expected to change significantly in less than a second. Also, interference patterns may perhaps be discemed by inspecting the data at a greater than $1 \mathrm{~Hz}$ rate. The $1 \mathrm{~Hz}$ output rate is believed to contribute error in interpreting the data. This error is not estimated.

Bias Error-The DASs were bench calibrated using an NREL-owned voltage source with an uncertainty, traceable to National Institute of Standards and Technology (NIST) standards, of less than $0.001 \%$. This uncertainty is neglected. Calibration took place in an air-conditioned environment, however, and resistors in the DAS are temperature dependent. Engineers at Instrumental Solutions estimate the higher operating temperature caused overpredictions of $4.0 \mathrm{~V}$ and 7.8 A. These uncertainties are included in the analysis.

\section{RESULTS}

0.2-km ACCELERATIONS-CarSim and SIMPLEV use similar approaches and levels of detail in modeling series HEVs, so we would expect that they agree very closely. One significant difference between the programs is the way they compute the power required at the wheels. Recall EQ (3), which computes power required at the battery from the road load. SIMPLEV takes the speed at the current time step as $v$ in this equation, while AeroVironment takes the average of the speed at the previous time step and the current time step as $v$. This causes AeroVironment to predict lower battery power requirements than SIMPLEV in cases where the previous speed is less than the current speed, as in positive accelerations. CarSim's implementation assumes that speeds corresponding to given time steps are known instantaneously; that is, at time $t=l s$, the vehicle speed is as is prescribed. This is equivalent to assuming that the speeds entered for given times are centered-in-time averages. SIMPLEV's implementation assumes that the speed corresponding to a given time step is the average speed over the time step preceding that instant. That is, the speed prescribed at time $t=1 \mathrm{~s}$ is the average speed from the times $\mathrm{t}=0$ to $\mathrm{t}=1 \mathrm{~s}$. See Figure 3.

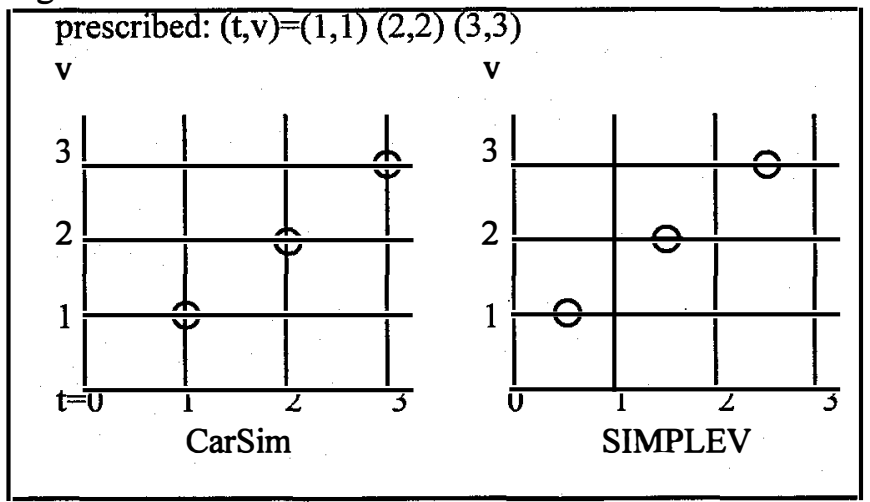

Figure 3. Speeds assumed by CarSim and SIMPLEV
Figure 4 shows the battery power computed by SIMPLEV and CarSim for Cal Poly-Pomona's vehicle over the acceleration run it completed in ZEV mode. The simulation programs use at these speeds at each time step. From time $t=0$ to $23 \mathrm{~s}$, SIMPLEV predicts higher powers than does CarSim. This is explained by the way SIMPLEV and CarSim use the speed inputs described above. As the difference between the speeds used by the programs at a given time step decreases, so does the difference between the calculated power use.

Figure 5 compares the battery power computed by SIMPLEV and CarSim for Cal Poly-Pomona's HEV acceleration run, where the internal combustion engine and generator are producing electric power. We again see CarSim predicting lower powers than SIMPLEV, and that the difference decreases as the rate of acceleration decreases. The roughly $10 \mathrm{~kW}$ discrepancy at 8 seconds is caused by the way the two simulations treat gear shifts. Both simulations predict a gear change between 7 and 8 seconds. CarSim uses the torque and RPM state before the gear shift to compute the time step's component efficiencies, while SIMPLEV uses torques and RPMs after the gear shift. The motor/controller efficiency before the shift (used in CarSim) was 0.95, while after the gear shift (as in SIMPLEV), the efficiency was 0.69. The lower efficiency in SIMPLEV at this point causes more power to be required of the battery.

Table 2 summarizes the energies computed and measured for Cal Poly-Pomona over acceleration runs and short return trips, which are not presented in Figures 4-7. The total trip time averaged about $53 \mathrm{~s}$. The data in the table indicate that SIMPLEV and CarSim agree to within $0.034 \mathrm{kWh}$ for a runs that require roughly $0.2 \mathrm{kWh}$ electrical energy. The table contains battery energies, equal to the electrical energy required by the motor, less the energy supplied by the generator. In the ZEV run, there is no energy supplied by the generator, and the battery energy is equal to the total electrical energy required. The total energy required by the motor depends on the trip and vehicle. Because the trips are very similar, (0.2-km maximum effort accelerations,) and the vehicle is unchanged, $0.2 \mathrm{kWh}$-electric is characteristic of both runs. The difference between CarSim and SIMPLEV is therefore $0.01 / 0.2 * 100=5 \%$.

Table 2. Battery Energy Use Computed and Measured for Cal Poly-Pomona

\begin{tabular}{|c|c|c|c|}
\hline & Measured $(\mathrm{kWh})$ & $\operatorname{CarSim}(\mathrm{kWh})$ & $\operatorname{SIMPLEV}(\mathrm{kWh})$ \\
\hline ZEV & $.198+.005 /-.018$ & $.208+.044 /-.047$ & $.218+.044 /-.047$ \\
\hline HEV & $.030+.003 /-.016$ & $.048+.080 /-.068$ & $.060+.080 /-.068$ \\
\hline
\end{tabular}

Modeled Versus Measured-The data in Table 2 show that the energy predictions of the two simulation programs agree with the measured energy use to within the error bounds on the data. The error bounds are large relative to the measured energy use, however, roughly $10 \%$ on measurements on the ZEV run, and $20 \%$ on simulation results for the same run. As mentioned above, the battery energy use for the HEV run does not represent the total electrical energy used; it is therefore not appropriate here for computing percent uncertainty. Uncertainties on the calculated energy use are larger for the HEV run than for the ZEV run because of the significant 
uncertainty assumed in the internal combustion engine/generator output.

Figure 6 shows the upper and lower bounds on measured and computed battery power for the ZEV acceleration run. The bounds are computed from measurement uncertainty for the measured data and from the estimated effects of uncertainty in measured speed (which is used as an input to the program) and input parameters. For readability, only

CarSim's results are shown. The shape of SIMPLEV's results curve is as shown in Figure 4, while the uncertainty at each point in SIMPLEV's results is similar to that uncertainty shown in CarSim's.

We see generally good agreement between the simulation and the measured data; in many sections CarSim's predictions fall within the uncertainty bounds on the measured power. Significant disagreement is seen at times $t=1$ second, 7 and $8 \mathrm{~s}$, and at $11 \mathrm{~s}$.

The spike in the measured power at $1 \mathrm{~s}$ is believed to be an error. The measured voltage at this point is $215 \mathrm{~V}, 71 \mathrm{~V}$ greater than the nominal pack voltage. We would expect the pack voltage to decrease from the no-load pack voltage as current is drawn from the batteries. Measured current at this time is $156 \mathrm{~A}$.

The downward spike at 7 and $8 \mathrm{~s}$ is believed to be accurate. Pack voltage at $7 \mathrm{~s}$ is measured at $122 \mathrm{~V}$, very close to what is measured during the deceleration at the end of this run, when the motor is off. This spike is caused by a gear shift, where the accelerator pedal is released for the shift. This downward spike occurs at roughly the same time and speed and for the same duration in two other Cal Poly-Pomona acceleration runs, including the HEV run considered. The downward spikes occur at roughly $45 \mathrm{~km} / \mathrm{h}$, which corresponds to a motor speed of 4500 RPM in Cal Poly-Pomona's first gear.

Neither CarSim nor SIMPLEV predicts this drop because the measured speed:does not decrease at this point. Previously mentioned uncertainty in the speed measurement is believed to be responsible. In particular, better resolution may have allowed the speed meter to measure a dip or lull.

Measured power dips below zero at $8 \mathrm{~s}$. Because the vehicle is not equipped with regenerative braking and its generator is not running, negative power must be an error.

The spike at 11 seconds is also believed to be an error. The measured pack voltage at this point is $250 \mathrm{~V}, 106 \mathrm{~V}$ greater than the nominal pack voltage. Measured current is $254 \mathrm{~A}$. $1 \mathrm{~s}$ before this point and $1 \mathrm{~s}$ after it, the measured pack voltage is roughly $110 \mathrm{~V}$ while the measured current varies by less than $6 \%$ among the three measurements.

Figure 5 shows the upper and lower bounds on measured and computed battery power for the HEV acceleration run. Again, only CarSim's results are shown.

The measured data jumps around at time $t=3,4$, and 5 seconds because the measured voltage jumps from 266 to 125 to $162 \mathrm{~V}$ while the current increases consistently from second to second. The 266 and $162 \mathrm{~V}$ measurements are taken to be erroneous as argued above.

The downward spike at 9 seconds is again believed to be caused by a shift, as the driver takes his foot off the accelerator. No lull in speed is measured, however, and therefore CarSim and SIMPLEV do not predict this spike.
CarSim does not predict the drop to negative power, which corresponds to charging the batteries by the generator set during deceleration following the run, at the same time as it is measured ( $t=17 \mathrm{~s}$ ) because of inconsistency in the data. From 16 to $17 \mathrm{~s}$, the measured battery power becomes negative but the measured speed increases. Therefore, CarSim and SIMPLEV calculate that power is drawn from the battery during this second.

58-km TRIP- Instrumental Solutions' voltage and current measurements were not believable for this trip (presumably because of interference from Penn State's AC motor and controller); it was therefore used only to measure speed. The Cruising Equipment kWh-meter was less sensitive to $\mathrm{AC}$ motor/controller interference on Penn State's and other vehicles, and its results are presented here.

Simulation Comparison-The difference between CarSim's and SIMPLEV's predicted energy use in Figures 4 and 5 was seen to decrease as the difference in their assumed speeds decreased. The 58-km range event contains only moderate accelerations, and as a result, the CarSim and SIMPLEV agree more closely. See Table 3.

Table 3 indicates battery energy computed by the programs for the measured speed profile on a flat surface. There are hills on the measured trip, but SIMPLEV is difficult to use for extended trips with elevation changes. SIMPLEV predicts higher energy use than CarSim by $2.6 \%$.

Table 3. SIMPLEV's and CarSim's Calculated Energy Use for the 58-km Event (no hills)

\begin{tabular}{|c|c|}
\hline SIMPLEV $(\mathrm{kWh})$ & $\operatorname{CarSim}(\mathrm{kWh})$ \\
\hline 7.55 & 7.36 \\
\hline
\end{tabular}

Measured Versus Modeled-Table 4 compares the measured energy use to CarSim's prediction when the measured speeds and known hills are input. CarSim's prediction is $10.0 \%$ greater than the measured energy. The large uncertainty in CarSim's result is likely due to the uncertainty in the effectiveness of the regenerative braking system. The uncertainty in Cal Poly-Pomona's calculated energy due to the uncertainty in parameters is roughly $10 \%$ for the ZEV run, and Penn State's is roughly $20 \%$. Penn State's vehicle includes regenerative braking and Cal Poly-Pomona's does not.

Table 4. Measured and Calculated Energy Use for the 58-km Event (hills included in model)

\begin{tabular}{|c|c|}
\hline Measured $(\mathrm{kWh})$ & $\operatorname{CarSim}(\mathrm{kWh})$ \\
\hline $7.36 \pm 0.74$ & $8.18+2.09 /-1.70$ \\
\hline
\end{tabular}

\section{CONCLUSIONS}

SIMPLEV 3.0 and CarSim 2.5.4 were used to simulate the performance of two student-assembled HEVs; one run on two $0.2-\mathrm{km}$ maximum effort accelerations, and the other on a 58$\mathrm{km}$ trip that includes hills. Speed and battery power and energy were measured. Input component parameters were estimated, and measured speed was input to the simulations to calculate second-by-second power, which was compared to measurement. Also, measurement uncertainties were 
estimated and propagated, and their effects on this comparison were estimated.

Careful uncertainty analysis is particularly important to a validation effort, whose goal is to determine how closely a computer simulation approximates actual experimentation. There are many uncertainty sources in an HEV simulation validation because of the complexity of an HEV. Propagating and analyzing these uncertainty is difficult; the work here is quite rough and involved many approximations.

Given the same inputs, SIMPLEV and CarSim make nearly identical power and energy use predictions. Because they use prescribed speeds differently in the basic vehicle dynamics equations, the difference between their power predictions depends on both acceleration and speed. As acceleration or speed (or both) decrease, so does the difference between the programs' predictions.

The programs considered predict ZEV and seriesconfigured HEV energy use to within the significant uncertainties $( \pm 50 \%)$ of this experiment.

\section{RECOMMENDATIONS}

HEV simulation codes must be carefully validated before being trusted. A careful validation includes accurate characterization of each HEV component, using NISTtraceable instruments. Accurate knowledge of the strategy for generator set output control is absolutely critical to an HEV simulation validation. Generator output is generally on the order of vehicle energy use and uncertainties in generator output may dominate the uncertainty of the experiment. The temperature and sensitivities of each component and the DAS must be understood. The DAS must be well insulated from electromagnetic interference, and should ideally be pre-tested in an environment with noisy electromagnetic interference (EMI) sources to determine its sensitivity to EMI.

The validation should include repeated runs on a precisely and accurately measured speed profile probably on a dynamometer, as well as road testing.

\section{REFERENCES}

1. Cole, G.H.,"SIMPLEV: A Simple Electric Vehicle Simulation Program Version 2.0", DOE/ID-10293-2, Idaho National Engineering Laboratory, Idaho Falls, Idaho, 1993.5. 2. Marr, W.W., W.J. Walsh, "An Electric/Hybrid Vehicle Model for Establishing Optimal Battery Requirements," Argonne National Labs, Argonne, Illinois, 1985.

3. Slusser, Ron, "ELVEC-An Electric/Hybrid Vehicle Performance Simulation Computer Program," EVC No. 8053, Electric Vehicle Council, Washington, D.C., 1980

4. Wimmer, Robert, "Hybrid 30 Computer Simulation Program for a Fuel Cell/Battery Powered Vehicle Operations Manual," Georgetown University, Washington DC, 1992

5. ANSI/ASME, "Measurement Uncerminty," PTC 19.11985, The American Society of Mechanical Engineers, New York, New York, 1985

6. "The AeroVironment Electric/Hybrid Vehicle Simulator CarSim 2.5.4," AeroVironment, Inc., Monrovia, California, 1994
7. Wells, Chester V., "Measurement Uncertainty Analysis: What It Is and How to Do It, with Examples," National Renewable Energy Laboratory, Seminar Presented to the Central Colorado Section of the Precision Measurements Association, Golden, Colorado 


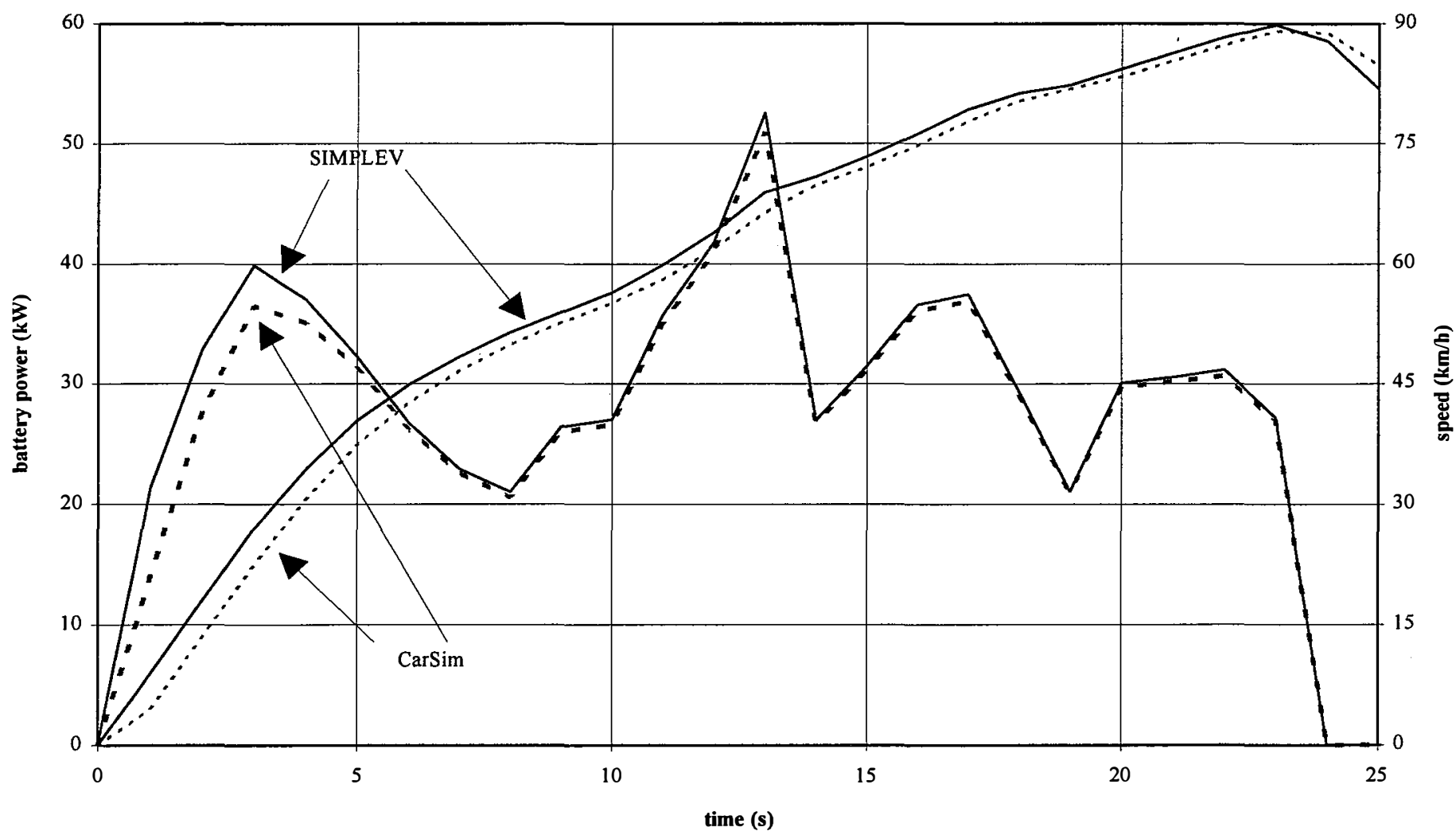

Figure 4. Simulated battery power for Cal Poly-Pomona's 0.2-km maximum effort acceleration, ZEV mode

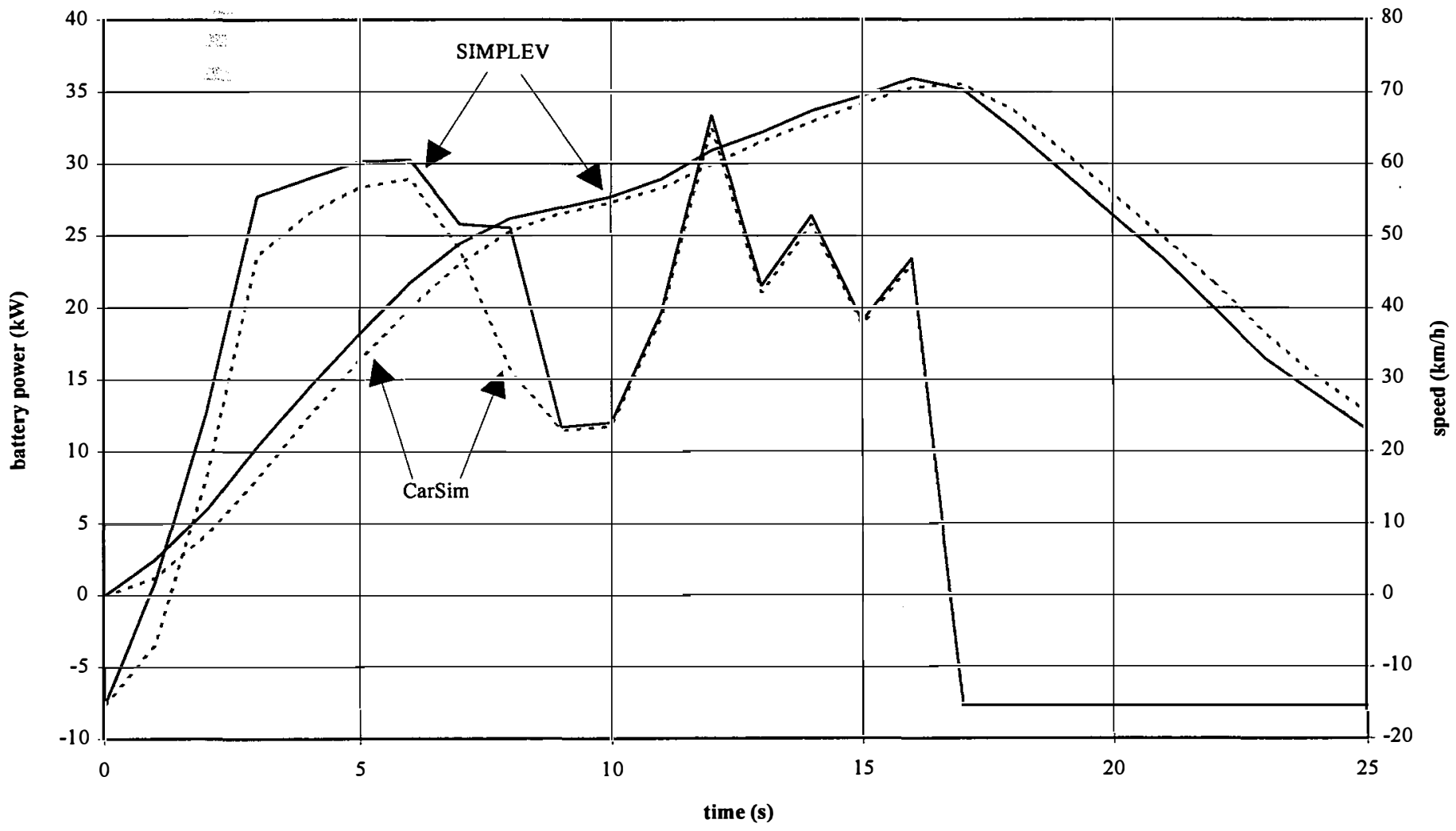

Figure 5. Simulated battery power for Cal Poly-Pomona's 0.2-km maximum effort acceleration, HEV mode 


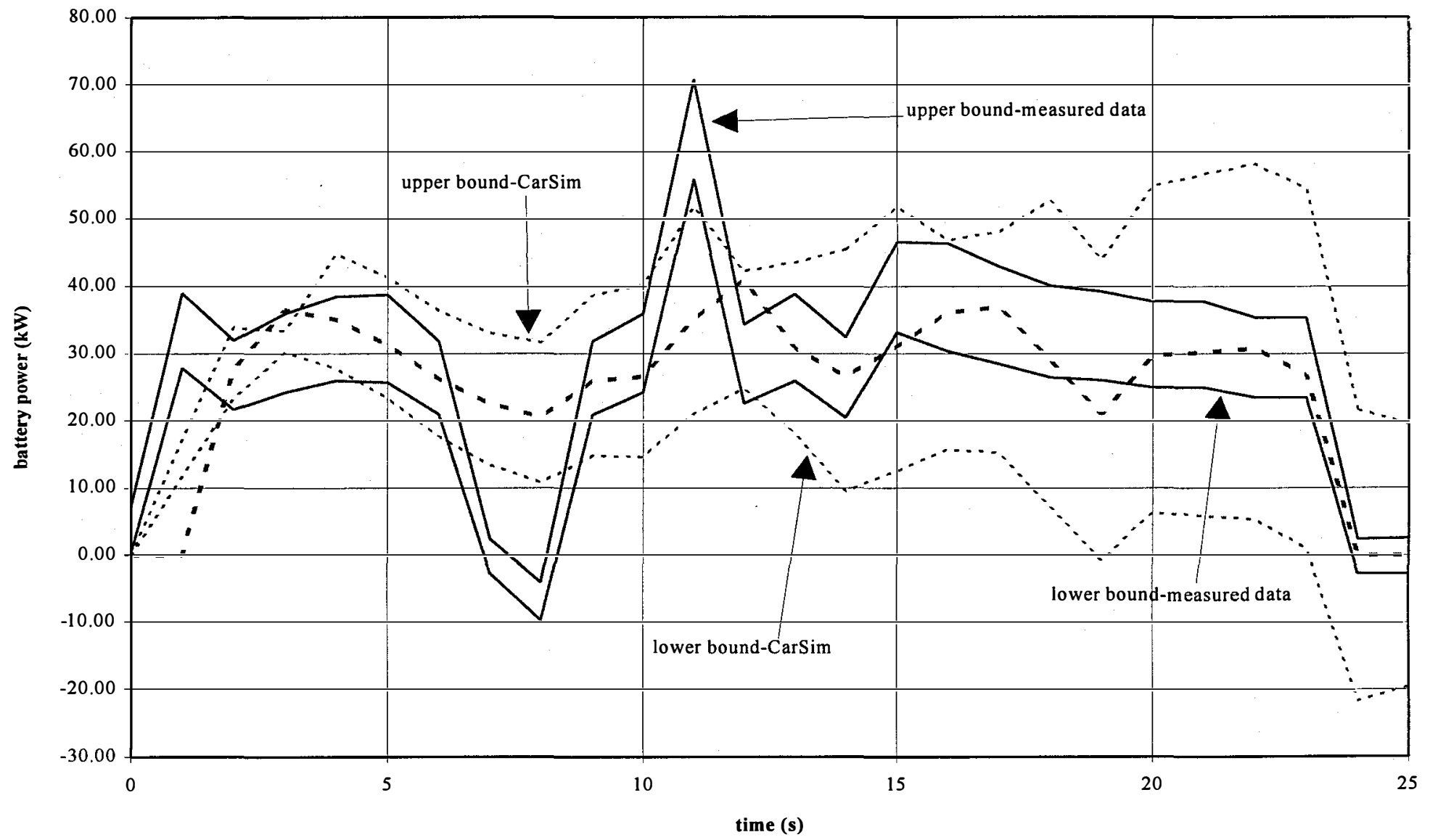

Figure 6. Measured and simulated battery power for Cal Poly-Pomona on 0.2-km maximum effort accleration, ZEV mode

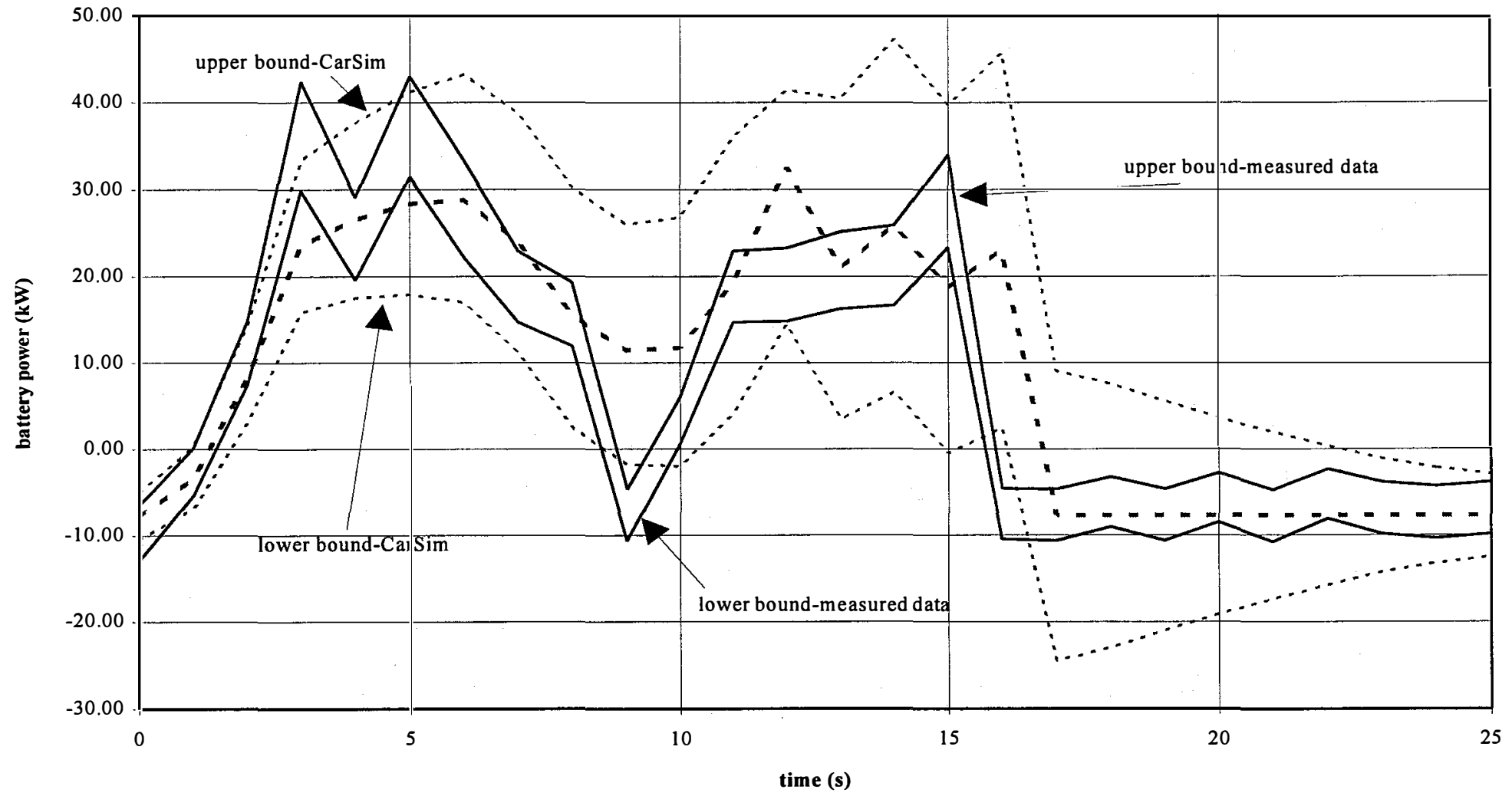

Figure 7. Measured and calculated battery power for Cal Poly-Pomona on 0.2-km maximum effort acceleration, HEV mode 